\title{
Fenómeno de acomodación inmunológica: Trasplante hepático ABO incompatible. Caso clínico
}

\author{
Lorena Castro $^{1}$, Andrés Yarur ${ }^{1}$, Roberto Segovia ${ }^{1,2}$, \\ Rodrigo Ponce ${ }^{1}$, Mario U ribe ${ }^{2}$, Mario Ferrario ${ }^{2}$, \\ Erwin Buckel$^{2}$, Hernán Iturriaga ${ }^{1}$. \\ Accomodation process: \\ ABO-incompatible liver transplantation. \\ Report of one case
}

We report a 33 year-old female with a diagnosis of halothaneinduce fulminant hepatic failure who was subjected to a liver transplant with an ABOincompatible graft. The patient received a therapeutic protocol that included total plasma exchange, splenectomy and quadruple immunosuppression. After 5 years, the patient remains asymptomatic and with normal liver enzymes, while she has been treated with low dose of immunosuppressive drugs. This case demonstrates an example of how the immunological process of accomodation opens the possibility of using ABO-incompatible organs as a definitive grafts (Rev Méd Chile 2009; 137: 1061-5).

(Key words: ABO Blood-group system; Allergy and Immunology; Liver transplantation)

Recibido el 14 de agosto, 2008. Aprobado el 26 de mayo, 2009.

Departamento de Medicina, Hospital San Borja-Arriarán ${ }^{1}$ y Unidad de Trasplante, Clínica Las Condes ${ }^{2}$. Facultad de Medicina, Universidad de Chile. Santiago de Chile.

$\mathrm{L}$ a hepatitis fulminante es una emergencia vital que suele requerir de un trasplante hepático, utilizando habitualmente un injerto ABO idéntico o compatible de un donante cadavérico. Sin embargo, dada la situación de urgencia médica y baja disponibilidad de órganos existe como alternativa el uso de donantes cadavéricos marginales, donantes vivos o de un injerto sin compatibilidad de grupo ABO. Se discutirá el caso de un paciente que requirió de un injerto $\mathrm{ABO}$ incompatible $\mathrm{y}$

Correspondencia a: Dr Roberto Segovia. Departamento Gastroenterología, Clínica Las Condes. Lo Fontecilla 441, Las Condes. Santiago Chile. Fono-Fax: 6108719.

E mail: rcasegovia@gmail.com que después de casi 5 años utilizando bajas dosis de inmunosupresión presenta pruebas hepáticas normales. Este fenómeno, dado a pesar del reconocimiento inmunológico del huésped, ha sido denominado "acomodación" inmunológica y será revisado a continuación.

\section{CASO CLÍNICO}

Mujer de 33 años sin morbilidad previa, proveniente de Puerto Varas. Fue sometida a colecistectomía laparoscópica electiva el 18 de julio de 2003 recibiendo anestesia con halotano. Evolucionó sin complicaciones y fue dada de alta. Al quinto día del postoperatorio presentó compromiso del esta- 
do general, náuseas, vómitos, ictericia y alteración de conciencia progresiva compatible con encefalopatía hepática, por lo cual se hospitalizó con el diagnóstico de hepatitis fulminante. El estudio etiológico viral, metabólico, autoinmune y de otras drogas resultó negativo. Fue trasladada a la Unidad del Paciente Crítico del Hospital Clínico San Borja Arriarán (HCSBA) el 5 de agosto de 2003 con el diagnóstico de hepatitis aguda fulminante por halotano y se activó como urgencia nacional para trasplante hepático. Dada la emergencia vital se efectuó un trasplante hepático de donante cadáver $\mathrm{ABO}$ incompatible (donante grupo A, receptor grupo O) el 8 de agosto de 2003, en Clínica Las Condes. El protocolo terapéutico consistió en plasmaféresis intra y postrasplante, esplenectomía e inmunosupresión cuádruple, con metilprednisolona, ciclofosfamida, timoglobulina y ciclosporina. El estudio histopatológico del explante concluyó necrosis submasiva.

La paciente recibió 5 sesiones de plasmaféresis, que disminuyó significativamente el título de isohemoglutininas anti A. Sin embargo, su incremento posterior no se tradujo en una injuria significativa al injerto (Figura 1).

En el postoperatorio temprano evolucionó con hemoperitoneo que requirió cirugía, y posteriormente una neumopatía aguda. Los estudios imagenológicos y de función hepática resultaron normales (Tabla 1). El egreso médico fue a los 54 días del trasplante, en buenas condiciones y con terapia inmunosupresora en base a ciclosporina, ciclofosfamida y predni- sona. En su evolución intrahospitalaria presentó infección por citomegalovirus en dos oportunidades tratadas satisfactoriamente, un rechazo agudo moderado corticoide-sensible y un bilioma que requirió drenaje bajo tomografía computarizada.

La paciente asiste a controles médicos periódicos y cumplió cinco años postrasplante. En la actualidad se encuentra desarrollando una vida laboralmente activa, con pruebas hepáticas normales, uso de inmunosupresión a dosis bajas (ciclosporina $200 \mathrm{mg} /$ día, azatioprina $100 \mathrm{mg} /$ día) y función renal conservada.

\section{DisCUSIÓN}

Desde el punto de vista inmunológico el hígado es un órgano que presenta ventajas comparativas con otros órganos en relación al trasplante. No requiere estudios de compatibilidad HLA y se ha descrito tolerancia en pacientes trasplantados que han abandonado la inmunosupresión. Por otra parte, el hígado tiene células hematopoyéticas y dendríticas que actúan como presentadoras de antígenos, presenta un doble sistema vascular de irrigación arterial y venoso, y además capacidad de regeneración. Estas características explican en parte los mecanismos de tolerancia inmunológica y la elevada sobrevida del injerto a largo plazo en el paciente trasplantado ${ }^{1}$.

La hepatitis fulminante constituye una emergencia médica donde la utilización de un injerto

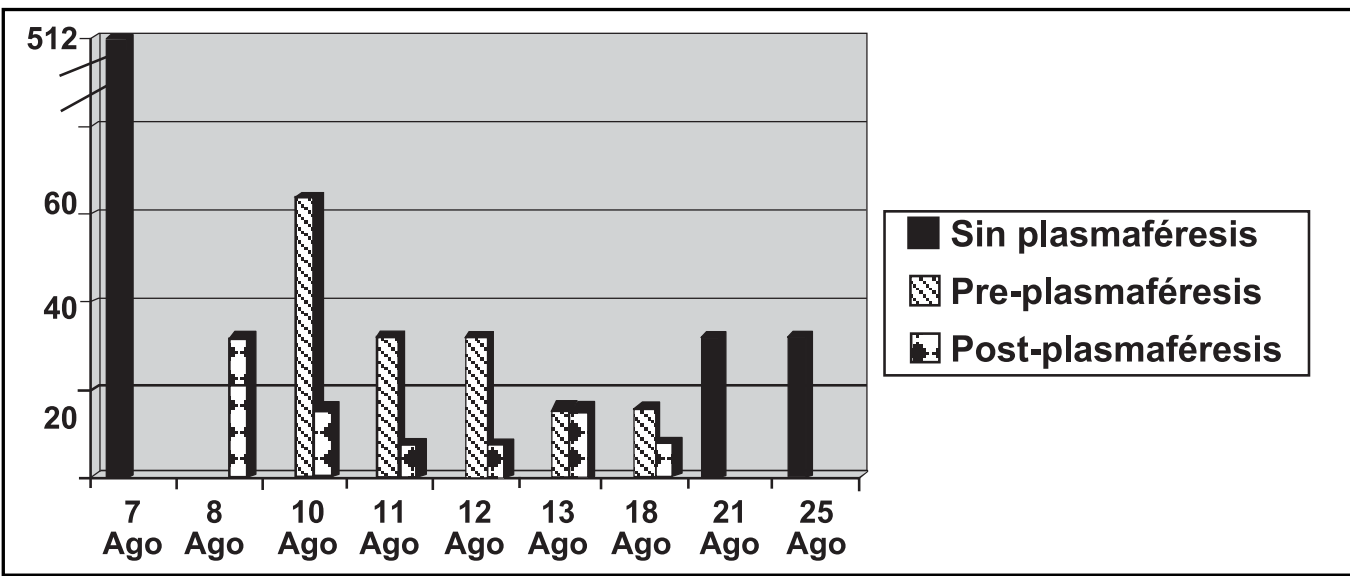

Figura 1. Título de inmunoglobulinas postrasplante (Ig G anti A). 
Tabla 1. Pruebas hepáticas

\begin{tabular}{|lrrccccc|}
\hline Variable & $\begin{array}{r}\text { Valor } \\
\text { referencia }\end{array}$ & Admisión & $\begin{array}{c}\text { Pre } \\
\text { trasplante }\end{array}$ & $\begin{array}{c}\mathbf{1} \text { mes } \\
\text { postrasplante }\end{array}$ & $\begin{array}{c}\mathbf{2} \text { meses } \\
\text { postrasplante }\end{array}$ & $\begin{array}{c}\mathbf{1} \text { año } \\
\text { postrasplante }\end{array}$ & $\begin{array}{c}\mathbf{5} \text { años } \\
\text { postrasplante }\end{array}$ \\
\hline Bil tot & $(0,0-1,1 \mathrm{mg} / \mathrm{dL})$ & 22 & 35 & 5,7 & 24 & 0,75 & 0,8 \\
AST & $(0-34 \mathrm{U} / \mathrm{L})$ & 600 & 98 & 36 & - & 54 & 38 \\
ALT & $(0-31 \mathrm{U} / \mathrm{L})$ & 1.788 & 449 & 29 & 130 & 71 & 30 \\
GGT & $(30-50 \mathrm{IU} / \mathrm{L})$ & 4.499 & 64 & 191 & - & 190 & - \\
FA & $(53-141 \mathrm{U} / \mathrm{L})$ & 212 & 141 & 473 & 1.258 & 223 & 147 \\
Prot & $(\%)$ & 9 & 19 & 71 & 100 & 78 & 80 \\
INR & & 14,4 & 5,83 & 1,34 & 1 & 1,22 & 1,19 \\
Creat & $(0,60-1,10 \mathrm{mg} / \mathrm{dL})$ & 1,0 & 0,9 & 0,45 & 1,8 & 1,4 & 1,15 \\
Alb & $(3,5-5,2 \mathrm{~g} / \mathrm{dL})$ & 2 & 2,1 & 2,8 & 2,8 & 3,4 & 4,3 \\
\hline
\end{tabular}

Abreviaciones: Bil Tot $=$ Bilirrubina total; AST $=$ Aspartato aminotransferasa; ALT $=$ Alanino aminotransferasa; GGT =Gama glutamil transpeptidasa; FA =Fosfatasas alcalinas; Prot =Protrombina; INR =Cuociente normalizado internacional; Creat $=$ Creatinina; Alb =Albúmina.

$\mathrm{ABO}$ incompatible surge como alternativa y en la cual es posible superar la barrera del rechazo humoral ${ }^{2,3}$. A diferencia del trasplante ABO compatible, en que puede presentarse un rechazo de tipo celular agudo, en esta modalidad se agrega el rechazo humoral agudo, que está gatillado por la unión de anticuerpos anti-A y anti-B preformados al endotelio del injerto, lo que genera la activación del complemento. Se desencadena así un proceso que lleva a la trombosis intravascular y posteriormente a la pérdida del órgano ${ }^{4}$.

Las frecuentes complicaciones vasculares y de la vía biliar del injerto, hacían que este tipo de trasplante fuese de excepción, con resultados significativamente inferiores a trasplantes compatibles en pacientes con hepatitis fulminante. Sin embargo, los estudios realizados en la última década no han demostrado diferencias significativas en la sobrevida tanto del injerto como del paciente. Un estudio canadiense reciente en pacientes con insuficiencia hepática aguda grave, mostró sobrevida del injerto de 56\%, 54\% y 60\% a los cinco años en trasplantes $\mathrm{ABO}$ incompatibles, compatibles e idénticos, respectivamente ${ }^{5}$.

Desde el inicio de los trasplantes ABO incompatibles se han utilizado diferentes modalidades terapéuticas para evitar el rechazo humoral.

La plasmaféresis, tiene por objetivo reducir los títulos de anticuerpos anti-A y anti-B a diluciones menores de $1 / 8$ a $1 / 32$ en las primeras dos semanas postrasplante. No está estandarizada aún la frecuencia y duración de esta terapia 5 .

La esplenectomía durante la cirugía del trasplante fue inicialmente considerada de rutina, dado que lograría disminuir el reservorio de células plasmáticas productoras de anticuerpos. Su utilización actualmente es controversial. El riesgo de muerte por sepsis puede disminuirse con el uso de vacunación contra bacterias encapsuladas ${ }^{4,6}$.

Existe un arsenal creciente de fármacos inmunosupresores con distintos mecanismos de acción en el proceso de activación del linfocito $\mathrm{T}$. Protocolos actuales utilizan esquemas multidroga, lo cual aumenta la eficacia y permite el uso de dosis bajas de cada fármaco, disminuyendo así la toxicidad $^{7}$. Se ha utilizado la infusión intrahepática de prostaglandina E1 y anticuerpo monoclonal anti CD20 (Rituximab). Este último podría utilizarse pretrasplante reemplazando la esplenectomía quirúrgica $^{8}$. Equivaldría a una "esplenectomía transitoria" en los primeros 6 meses postrasplante. Se requieren futuros estudios para su validación?.

Desde 1992 se utiliza un protocolo en los receptores de trasplante $\mathrm{ABO}$ incompatible basado en la evidencia obtenida en trasplante renal. Este consiste en plasmaféresis intra y postrasplante (durante las primeras 2 semanas), esplenecto- 
mía e inmunosupresión de inducción y tetraterapia de mantención para reducir la producción de anticuerpos y el riesgo del rechazo tanto humoral como celular ${ }^{4}$.

Existe un fenómeno inmunológico por el que el ascenso de los niveles de isohemaglutininas postrasplante no generen un rechazo humoral, que podría explicar el éxito del trasplante en presencia de incompatibilidad del grupo sanguíneo ABO. Este proceso llamado "acomodación" inmunológica se define como la resistencia adquirida de un órgano o tejido a la injuria mediada inmunológicamente. Es así como la función del órgano trasplantado se mantiene en forma normal a pesar de la presencia de anticuerpos específi$\cos ^{4,5,10,11}$. Se describe además un activo proceso de quimerismo, cuyo conocimiento está en desarrollo.

El concepto de "acomodación" debe diferenciarse de "tolerancia" inmunológica, donde la respuesta inmune contra determinado antígeno es selectivamente abolida, resultando en una norespuesta ${ }^{11}$.

Los mecanismos inmunológicos subyacentes al proceso de "acomodación" no han sido del todo dilucidados aunque existen algunas evidencias ${ }^{11}$.

La estructura sacárida del antígeno ABO puede presentar discretos cambios disminuyendo la unión del anticuerpo después del trasplante. Existiría un mayor control sobre la actividad del complemento al eliminarse el complejo final del mismo, o bien inhibiendo la cascada ${ }^{12}$. Se ha observado la sobreexpresión de sustancias protectoras naturales como el heparán-sulfato en injertos con proceso de acomodación que genera carga negativa a la superficie celular que disminuiría la activación del complemento. Además tiene efecto antioxidante y anticoagulante natural ${ }^{13,14}$.

Se ha planteado la generación tanto de up como down-regulation de algunos genes relacio-

\section{REFERENCIAS}

1. Pefaur J, Toro J. $1^{\text {er }}$ Curso de Trasplantes año 2000. En: Pefaur J, Toro J editores. Santiago, Chile: Editorial Archives \& Abstracts; 2001. p: 113.

2. Alexandre GP, Squifflet JP, De Bruyère M, Latinne D, Reding R, Gianello P et al. Present experiences in a series of 26 ABO-incompatible living donor renal allografts. Transplant Proc 1987; 19: 4538-42. nados con el proceso de acomodación. Entre los protectores figuran los genes hemo-oxigenasa 1, A20, Bcl-2 y Bcl-xL. Mientras, genes reconocidos como pro- apoptóticos, Bad y Bax, se expresan en injertos que presentan rechazo agudo, así como también TNF $\beta$, TGF $\beta$ y SMAD5, todos ellos con acción proinflamatoria ${ }^{15,16}$.

Respecto a la acomodación del receptor frente al injerto se ha observado un cambio en la especificidad de los anticuerpos del receptor. La subclase IgG1, sería reemplazada por el tipo IgG2, que es menos eficiente. Además predomina el ambiente de citoquinas dado por un cambio de respuesta Th1 a Th2 con un incremento de producción de IL-4, IL-10 e IL-13 $3^{17,18}$.

La "acomodación" pudiera cumplir un papel protector en el trasplante de órganos cuando se realiza con incompatibilidad de grupo ABO. Sin embargo, existe un riesgo teórico dado que evitaría la eliminación eficiente de patógenos como de tumores, cuya real participación no ha sido definida ${ }^{19}$.

La relevancia de este caso es que constituye el primer reporte de trasplante hepático ABO incompatible en nuestro país, planteado inicialmente como terapia de rescate en espera de un donante compatible y constituyéndose, posteriormente, en un órgano definitivo.

La favorable evolución del caso establece la potencial utilización de injertos $\mathrm{ABO}$ incompatibles como alternativa terapéutica en situaciones de emergencia. Tanto la disponibilidad actual de inmunosupresores como el mayor conocimiento de los procesos de "adaptación" inmunológica permitirán avalar esta modalidad terapéutica, no sólo como un evento transitorio o puente hasta obtener un segundo injerto compatible, solucionando así la emergencia de la insuficiencia hepática, sino como para constituirse en el órgano definitivo.

3. Gugenheim J, Samuel D, Reynes M, Bismuth H. Liver transplantation across ABO blood group barriers. Lancet 1990; 336: 519-23.

4. Hanto DW, Fecteau AH, Alonso MH, Valente JF, Whiting JF. ABO-incompatible liver transplantation with no immunological graft losses using total plasma exchange, splenectomy and quadruple immunosuppression: evidence for accommodation. Liver Transpl 2003; 9: 22-31. 
5. Tosso C, Al-Qahtani M, Alsaif FA, Bigam Dl, Meeberg GA, James Shapiro AM et al. ABO-incompatible liver transplantation for critically ill adult patients. Transpl Int 2007; 20: 675-81.

6. Alexandre GPJ, Squifflet JP, De Bruyère M, Latinne M, Moriau M, Ikalou N et al. Splenectomy as a prerequisite for successful human ABO-incompatible renal transplantation. Transplant Proc 1985; 17: 138-43.

7. Fung J, Dympna K, Kadry Z, Patel-Tom K, Eghtesad B. Immunosuppression in liver transplantation: beyond calcineurin inhibitors. Liver Transplant 2005; 11 : 267-80.

8. Usui M, isaji S, Mizuno S, Sakurai H, Uemoto S. Experiences and problems pre-operative anti-CD20 monoclonal antibody infusion therapy with splenectomy and plasma exchange for ABO-incompatible living-donor liver transplantation. Clin Transplant 2007; 21: 24-31.

9. Sonnenday CJ, Warren DS, Cooper M, Samaniego M, HaAs M, King KE et al. Plasmapheresis, CMV hyperimmune globulin, and anti-CD20 allow ABO-incompatible renal transplantation without splenectomay. J Transplant 2004; 4: 1315-22.

10. WARNER PR, NeSTER TA. ABO-incompatible solidorgan transplantation. Am J Clin Pathol 2006; 125: 87-94.

11. Koch CA, Khalpey ZI, Platt JL. Accommodation: preventing injury in transplantation and disease. J Immunol 2004; 172: 5143-8.

12. Ulfyin A, Backer AE, Clausen H, Hakomori S, Rydberg L, SAmuelsson BE ET AL. Expression of glycolipid blood group antigen in single human kidneys: change in antigen expression of rejected $\mathrm{ABO}$ incompatible kidney grafts. Kidney Int 1993; 44 : 1289-97.

13. Platt Jl, Vercellotti GM, Lindman BJ, Oegema tr, BaChand FH, Dalmasso AP. Release of heparin sulfate from endothelial cells: implications for pathogenesis of hyperacute rejection. J Exp Med 1990; 171: 1363-8.

14. SaAdi S, Wrenshall LE, Platt JL. Regional manifestations and control of the immune system. FASEB J 2002; 16: 849-56.

15. Salama AD, Delikouras A, Pusey CD, Cook HT, Bhangal G, Lechler RI et al. Transplant accommodation in highly sensitized patients: a potential role for Bcl-xL and alloantibody. Am J Transplant 2001; 1 : 260-9.

16. Park WD, Grande JP, Ninova D, Nath KA, Platt JL, GLOOR JM ET AL. Accommodation in ABO-incompatible kidney allografts, a novel mechanism of selfprotectin against antibody-mediated injury. Am J Transplant 2003; 3: 952-60.

17. Mohiuddin MM, Ogawa H, Yin DP, Shen J, Galili U. Antibody mediated accommodation of heart grafts expressing an incompatible carbohydrate antigen. Transplantation 2003; 75: 258-62.

18. Bach FH, Ferran C, Hechenleitner P, Mark W, KoyamaDa N, Miyatake T et al. Accommodation of vascularized xenografts: expression of "protective genes" by donor endothelial cells in a host TH2 cytokine environment. Nat Med 1997; 3: 196-204.

19. Otterbein LE, Soares MP, Yamashita K, Bach FH. Heme oxigenase 1: unleashing the protective properties of heme. Trends Immunol 2003; 24: 449-55. 